\title{
Fanfiction e Hiperficção: uma proposta para criação de narrativas colaborativas
}

\section{Fanfiction and Hiperfiction: A proposal for collaborative narratives creation}

PERES, Carolina Alves; Graduanda; Universidade Federal de Pelotas

carolinaaperes@gmail.com

FARIA, Mônica Lima de; Doutora; Universidade Federal de Pelotas

monicalfaria@gmail.com

\section{Resumo}

Este trabalho visa compreender os motivos que impulsionam a escrita de fanfictions, e as possíveis abordagens criadas a partir dos contextos narrativos existentes. Busca-se estudar o método como as narrativas podem ser construídas colaborativamente, objetivando relacionar o processo de escrita de fanfictions com as narrativas hiperficcionais. Assim, utiliza-se o design como ferramenta capaz de auxiliar o projeto de escrita colaborativa e, tendo em vista que a interface exerce um papel importante no estímulo da produção criativa, propõe-se a elaboração de uma plataforma projetada para contribuir com a criação de narrativas colaborativas.

Palavras Chave: fanfiction; hiperficç̧ão; colaboratividade.

\section{Abstract}

This paper aims to understand the reasons that drive the writing of fanfictions, and the possible approaches created from the existing narrative contexts. It is tried to study the method as the narratives can be constructed collaboratively, aiming to relate the process of writing of fanfictions with the hyperficcional narratives. Thus, the design is used as a tool capable of supporting the collaborative writing project and, since the interface plays an important role in the stimulation of creative production, it is proposed the elaboration of a platform designed to contribute to the creation of collaborative narratives.

Keywords: fanfiction; hiperfiction; colaborativity. 


\section{Introdução}

Existem muitos estímulos que impulsionam o início de uma leitura. Comumente as histórias são utilizadas no ensino de comportamentos dentro da comunidade, como forma de discutir morais e valores, ou até mesmo para satisfazer curiosidades. Elas têm o papel de dramatizar relações sociais e problemas de convívio, propagar ideias e expressar fantasias (EISNER, 2013). Também possuem um papel fundamental para o entretenimento, uma vez que leitores iniciam uma obra à procura de um universo fictício que promova imersão e propicie uma série de sentimentos e sensações referentes às palavras do narrador.

Ao ler uma história se produz sentido, se interpreta, se fantasia e vivência o texto lido. De acordo com Chartier (1998, p. 77) "a leitura é sempre apropriação, invenção e produção de significados [...] Toda história da leitura supõe, em seu princípio, esta liberdade do leitor que desloca e subverte aquilo que o livro lhe pretende impor". Os leitores possuem essa liberdade de imaginativamente criar hipóteses através das lacunas que são deixadas no enredo, criando deslocamentos e apropriações para além do texto original.

A web 2.0 representa um grande impacto na propagação e produção de conteúdos criados a partir destes deslocamentos e apropriações, o modo como as histórias são consumidas muda com o surgimento da possibilidade de interferir na narrativa desenvolvendo novas versões para o enredo colaborativamente. Plataformas para auto publicação de histórias, redes sociais e fóruns, são alguns dos exemplos que oferecem espaços que possibilitam o usuário a desenvolver suas visões sobre uma narrativa existente, ou ainda experienciar o processo de criação de uma narrativa original.

Este estudo objetiva discutir o processo de escrita de fanfictions e quais são as semelhanças encontradas com a hiperfiç̧ão, buscando reconhecer a prática de escrita colaborativa entre os fãs como um processo hiperficcional. Utilizando o design como uma ferramenta facilitadora para promover a experiência colaborativa e entendendo que a interface atua ativamente no estímulo da produção criativa, busca-se através da oportunidade encontrada, desenvolver uma plataforma voltada exclusivamente para a criação de narrativas colaborativas.

\section{Desenvolvimento}

\subsection{Fanfictions}

Inspirados pela criatividade, curiosidade e principalmente pela "possibilidade de prolongar a fruição daquele universo, experienciar mais elementos que não foram abordados pela história original e ler ou criar caminhos alternativos de interpretação" (SAMPAIO, 2013, p. 91) os leitoresautores iniciam a escrita de fanfictions ${ }^{1}$, que são definidas como:

escrita na qual os fãs usam narrativas midiáticas ou ícones culturais como inspiração para criar seus próprios textos. Em tais textos, os fãs autores imaginativamente estendem o enredo ou a cronologia original (...), criam novos personagens (...), e/ou desenvolvem novos relacionamentos entre personagens já presentes na fonte original (BLACK, 2006, p.3).

\footnotetext{
${ }^{1}$ Neste trabalho, as expressões fanfictions e fanfic serão utilizadas com frequência, portanto esta dispensará o uso do itálico.
} 
Sendo um gênero textual digital muito popular entre adolescentes, no qual a escrita ocorre com base nas possibilidades de compartilhamento que a tecnologia oferece aos leitores, as fanfics são um método para abordar novos contextos dentro de uma narrativa popular já existente. Esta prática é reconhecida dentro dos fandoms, que podem ser definidos como "o grupo social dos fãs de determinado produto (narrativo ou não), que desenvolve práticas específicas em relação ao seu objeto de afeto" (MURAKAMI, 2016, p. 6). Os fãs possuem a habilidade de tornar a recepção das obras, que a princípio seria passiva, em algo bastante participativo, produzindo diversos novos enredos sobre o mesmo material, pois não se limitam a escrever apenas uma fanfic, mas sim quantas forem necessárias para abordar todos os contextos imaginários que pensaram.

Murakami (2016, p. 15) observa que a cultura do fandom e das fanfictions, tal como são conhecidas atualmente, existe desde a década de 1960, tendo como o maior representante da época o fandom de Star Trek, em português "Jornada nas estrelas". É no final da década de 1990, após a difusão da internet, que os fãs começam a construir suportes para facilitar a visualização destas fanfictions, tais como sites, blogs e fóruns virtuais, alguns limitados a fandoms específicos e outros abertos para diversos fãs. No Brasil, de acordo com Vargas (2015), esse processo de escrita ganhou força após o lançamento da obra produzida por J.K Rowling, Harry Potter e a Pedra Filosofal. Tais dados foram evidenciados devido ao fato que

\begin{abstract}
a partir de 2000 [...] há uma profusão de websites dedicados a fanfictions de Harry Potter, levando a crer que o número de pessoas dispostas a gastar suas horas de lazer envolvidas em processos de leitura e escrita e seu compartilhamento on-line com outras pessoas que desfrutam do mesmo gosto aumentou de maneira significativa (VARGAS, 2015, p. 13-14).
\end{abstract}

Os fãs da série produziam enredos envolventes sobre parcelas não abordadas na história original, principalmente seguindo pontos de vista de personagens secundários, que não alteravam o enredo oficial da série. Ainda assim, é inegável a existência de fanfictions que diferem do contexto da obra principal, sugerindo ou não mudanças da história em que é baseada. Como constata Vargas,

os autores de fanfictions dedicam-se a escrevê-las em virtude de terem desenvolvido laços afetivos tão fortes com o original, que não lhes basta consumir o material que lhes é disponibilizado, passa a haver a necessidade de interagir, interferir naquele universo ficcional, de deixar sua marca de autoria (2015, p. 21-22).

Além de todos os motivos que situam a escrita de fanfictions, esta também é uma prática capaz de promover visibilidade à escrita amadora. Muitos autores se originam justamente deste contexto, aperfeiçoando suas técnicas de escrita e construção narrativa antes de lançarem suas obras.

Em seu livro de 1992, "Textual Poachers", Henry Jenkins (apud VARGAS, 2015) lista e conceitua os dez sentidos de reinterpretação a respeito dos fandoms. Esta pesquisa utilizará a obra de Naruto $^{2}$ para exemplificar as abordagens que podem ser utilizadas na construção das histórias.

1. Recontextualização: é a escrita de histórias que preenchem os espaços deixados nas narrativas originais. Geralmente essas cenas extras servem como auxílio para

\footnotetext{
2 Mangá de Masashi Kishimoto que retrata a história de Naruto Uzumaki, um jovem ninja que busca por reconhecimento e aprovação. Seu maior sonho é tornar-se Hokage, que significa ser o líder ninja mais forte da aldeia a qual pertence.
} 
explicar ou justificar condutas de determinados personagens, que causam surpresa ou perplexidade aos fãs.

No capítulo 699 do mangá Naruto, a história termina com Sasuke reconhecendo a amizade de Naruto, e se despedindo para então partir em sua viagem de redenção após a grande guerra ninja. Já no capítulo 700 a história avançou cerca de doze anos e cada personagem já formou sua família. Muitos possuem filhos e o capítulo tem como foco apresentar brevemente a vida atual de cada um. Existem diversas fanfics que preenchem esse espaço de tempo e explicam, por exemplo, como Sakura e Sasuke casaram e vieram a ter uma filha, tendo em vista a trajetória e comportamento dos personagens ao longo da série, ou retratam como Naruto veio a tornar-se Hokage, já que no fim do capítulo 699 ele apenas estava estudando para isso.

2. Expansão da linha do tempo: constantemente as obras oferecem pistas sobre fatos que ocorreram anteriormente ao início da narrativa. Os fãs utilizam estes fragmentos apresentados sobre o passado para desenvolver suas histórias do início até o momento em que a narrativa original se inicia, principalmente para destacar a evolução de cada personagem dentro daquele contexto.

Quando a história de Naruto se inicia no mangá original é contado que seu pai, o quarto Hokage, veio a falecer quando selou a raposa de nove caudas dentro do Naruto no dia de seu nascimento. A partir disto a história avança para quando Naruto já está com cerca de seus doze anos e ganha sua bandana ninja. São desenvolvidas fanfics que expandem essa linha do tempo contando como Minato, o quarto Hokage, batalhou para conseguir seu posto como ninja mais forte da vila, e se ele era um bom Hokage.

3. Refocalização: quando o autor de fanfiction centra sua história em um personagem secundário e pouco explorado pelo roteiro original, para mudar o foco principal da trama e até a ideologia.

Existem enredos narrativos que colocam Sakura como personagem principal, criando tramas com inimigos poderosos que ela precisa lutar bravamente para superar. Mesmo Sakura sendo tecnicamente um dos personagens principais do mangá, sua aparição é um pouco secundária, visto que os holofotes estão sempre virados para Naruto ou Sasuke e quando existe a oportunidade de amadurecer a personagem em cenas de bravura, geralmente seus atos heróicos são destruídos no momento em que se torna necessário que os personagens masculinos a salvem. Por este motivo, muitos fãs, principalmente do sexo feminino criam histórias em que Sakura se mostra forte e destemida como é em Naruto Shippuden.

4. Realinhamento moral: Vargas (2015) enfatiza que esta abordagem também é denominada por Jenkins como "refocalização levada ao extremo", devido ao fato que o universo moral do texto é colocado em questionamento e até transformado de forma invertida, tornando muitas vezes o herói em alguém que pode cometer atos maléficos. Em outros exemplos encontra-se o vilão como o personagem principal, que apesar de continuar cometendo atos não considerados bons. Tem 
explicada sua história, criando uma expansão da linha do tempo que passa a justificar suas escolhas e comportamentos na história original.

Como exemplo pode-se utilizar as fanfics que retratam os experimentos que Orochimaru faz com os humanos, em outro ponto de vista, valorizando a pesquisa e justificando porque ele realizou mutações genéticas transformando algumas pessoas em monstros.

5. Troca de gênero: em geral muitos fãs tendem a desenvolver romances em histórias que não pertencem a este gênero, ou não exploram essa área, tornando a narrativa do gênero romance. Isto pode acontecer com qualquer gênero diferente que seja explorado.

Esse é talvez um dos sentidos de reinterpretação que mais aparecem nas fanfics de Naruto. Os gêneros da série são aventura, comédia e fantasia, mas frequentemente aparecem histórias produzidas por fãs que idealizam o romance entre Sasuke e Sakura. Apesar dos personagens formarem uma família nos episódios finais da série, em nenhum momento durante o mangá eles possuem um vínculo amoroso. É muito mais uma relação de amor platônico por parte de Sakura. O personagem Sasuke aparece mais determinado a desenvolver suas habilidades ninjas para vingar seu clã e quebrar os laços de amizade que construiu com Naruto, Sakura e Kakashi. Nas histórias desenvolvidas pelos fãs esse relacionamento é desenvolvido muito antes que na cronologia real da série, e são modificados também a personalidade dos personagens para justificar seus atos dentro da narrativa.

6. Cross over: consiste no cruzamento de histórias, personagens e universos ficcionais, os fazendo coexistir em contextos diferentes daqueles abordados na narrativa original.

"Sob a aurora" é uma escrita criativa desenvolvida pelos fãs que mistura o universo de Naruto com as figuras da mitologia nórdica. Determinados personagens são transformados em bravos vikings que possuem adoração por Odin, enquanto alguns dos elementos e kekkei genkais ${ }^{3}$ ninja são mantidos como na obra original.

7. Deslocamento de personagem: conhecido também como o gênero de universo alternativo, é quando os personagens são retirados de seu contexto original e colocados em situações e épocas diferentes, podendo não corresponder a sua personalidade original, ou também manter características previamente definidas pelo autor da trama.

Algumas fanfics trazem os personagens de Naruto para o universo real. Estes são transformados estudantes de universidades, CEO's de grandes empresas, etc. Outras exploram o universo alternativo antes de 1900, as épocas das batalhas de espadas, da monarquia e dos conflitos internos dentro da realeza. Um exemplo é a fanfic "O general", que retrata a Inglaterra de 1845.

8. Personalização: acontece quando o autor de fanfiction quebra as barreiras entre a ficção e a realidade se inserindo como personagem no universo da história. "É tão

\footnotetext{
${ }^{3}$ Habilidades que são passadas geneticamente e são específicas em cada clã.
} 
forte o apelo daquele universo ficcional ao fã, que não basta escrever sobre ele; é preciso inserir a si mesmo como seu participante, concretizando, ainda que parcialmente, a fantasia de ser parte de determinada história" (VARGAS, 2015, p. 71).

Alguns fãs criam personagens adicionais nas fanfics que são representações de si mesmos. Eles escolhem ou criam seus próprios clãs e se inserem no ciclo de amizades dos protagonistas, desenvolvendo missões juntos ou participando da mesma equipe ninja.

9. Intensificação emocional: trata-se de histórias onde a parcela psicológica dos personagens é supervalorizada, e são enfatizados momentos de tristeza, dor e angústia, seguidos por sentimentos de conforto emocional. Jenkins acredita que estas histórias sobre situações angustiantes permitem aos fãs a expressão de suas preocupações relacionadas aos personagens, criando muitas vezes finais felizes para situações de desespero.

Um exemplo são as fanfics que retratam a parcela psicológica, falando sobre as emoções e pensamentos de Itachi ao ter que assassinar o próprio clã para garantir o bem da vila e seus moradores, tendo como clímax do enredo o assassinato dos próprios pais, mas não tem coragem de assassinar o irmão.

10. Erotização: é quando o aspecto erótico dos personagens é explorado e enfatizado, criando histórias apenas para maiores de 18 anos por conterem cenas de sexo explícito. Algumas histórias se originam a partir de pistas deixadas no contexto original, outras projetam comportamentos inesperados para aqueles personagens. Em geral, esse sentido de reinterpretação é acompanhado pela troca de gênero da obra original. Algumas dessas histórias são denominadas como shortfics, que são as fanfics curtas, com poucas palavras, que na maioria das vezes só contextualizam o espaço e descrevem o ato. Mas também existem longfics, conhecidas também como histórias longas com cerca de mais de 20 mil palavras, que incorporam aspectos de erotização no desenrolar da trama.

A mistura e união de vários desses sentidos de reinterpretação em uma única história é algo comum. Dificilmente estes irão aparecer isolados, pois geralmente as fanfics apresentam diversos elementos que contemplam duas ou mais das abordagens conceituadas por Jenkins. Esses sentidos indicam a necessidade por parte dos fãs de explorarem mais a narrativa, traçarem decisões diferentes e vivenciarem os rumos para os personagens.

Os jovens acostumados com a interatividade dos jogos e demais mídias, são participantes ativos que contribuem para a expansão das narrativas. Nos fóruns, os leitores-autores criavam histórias de modo colaborativo, cada parágrafo, ou capítulo era produzido por uma pessoa diferente, que por vezes controlava apenas um personagem, ou, em outras, o enredo inteiro. Atualmente, sites de auto publicação de histórias já oferecem essa possibilidade. Esse processo tem características que se assemelham ao jogo, uma vez que é necessária a interação por parte dos usuários para existir a continuidade e fruição da narrativa.

As formas como a leitura e escrita colaborativa se constroem nas fanfictions são identificadas como um processo semelhante às ações desempenhadas pelo usuário na leitura e 
criação do gênero textual hiperficção.

\subsection{Hiperficção}

A hiperficção é uma narrativa não-linear (ou multilinear), cujo enredo é construído por meio de caminhos hipertextuais, que são sinalizados por links, os quais o leitor tem a liberdade de escolher (ou não) acessar (SANTOS, VERGANO-JUNGER, 2015). Para Barbosa (2008), a hiperficção é como uma estrutura em labirinto, na qual a intervenção do leitor irá formar um percurso único modelando sua estrutura como melhor lhe convém. Essa intervenção do leitor se dá através da interação, visto que, uma narrativa em hiperfiç̧ão utiliza a interatividade para estabelecer a relação entre leitor e texto.

Na hiperficção, a interatividade se constrói a partir da própria estrutura narrativa, pois, o leitor é chamado a conectar fragmentos textuais, montando uma rede formada por episódios aparentemente descontínuos, exercitando assim, o seu poder de escolha (SANTOS, 2009, p. 78).

Pavão (2014) observa que ao ler uma história tradicional, navega-se entre uma única sequência de acontecimentos. Por consequência disto, é fácil perceber o início, meio e fim dentro da estrutura narrativa, devido à existência dessa ordem discursiva de leitura, de história e de mundo a ser representada, a qual todos os elementos são derivados uns dos outros e relacionamse entre si. Diferente da estrutura tradicional de leitura, "a hiperficção segmenta a narrativa em itens, lexias, fragmentos de texto e, depois, permite que o leitor possa percorrê-los na ordem que pensar ser mais conveniente" (PAVÃO, 2014, p. 142) e, tratando-se de um texto não linear, evidencia-se sua flexibilidade.

Logo, esse gênero narrativo oferece opções pelas quais é necessário que o leitor escolha, ou até mesmo rejeite, para dar sequência à leitura. Consequentemente, "a hiperficção dá ao leitor a chance de compartilhar o controle do texto juntamente com o autor" (SANTOS, 2014, p. 65) e, por este motivo, são necessárias estratégias cognitivas e metacognitivas para que a leitura seja realizada. Santos (2014) pontua ainda outros aspectos que devem ser levados em consideração como atenção, percepção, proposição de objetivos e de hipóteses (com sua consequente validação), ativação de esquemas, captação, organização e controle da informação. Sugerindo um design de narrativa. A leitura torna-se um exercício similar ao jogar um jogo.

As fanfictions são como extensões do texto original, mas com eventos e personagens que nem sempre são reconhecidos pelo autor da obra. A experiência de ler a narrativa oficial e depois navegar em uma série de enredos que se derivam e complementam as palavras do autor, são uma forma multilinear de leitura. No entanto, a maior diferença entre as fanfictions e a hiperfiç̧ão são as delimitações do autor. Na hiperficção o autor determina tudo aquilo que os leitores podem ou não experienciar, as fanfics não possuem esse controle, uma vez que são os leitores que criam as ramificações e diferentes enredos. Mas, se observada a prática de construção de fanfictions colaborativas, encontram-se similaridades com as noções de hiperficcção colaborativa.

A hiperfiç̧ão colaborativa, como o nome já diz, é uma narrativa de caráter coletivo construída por diversos autores, não apresenta links e a interação ocorre na medida em que os leitores-autores desenvolvem o texto juntos, tornando-se, muitas vezes, personagens no enredo. Essa prática era muito vista antigamente em fóruns e até mesmo nas comunidades do Orkut ${ }^{4}$, mas

\footnotetext{
${ }^{4}$ Antiga rede social filiada ao Google, desativada em 30 de setembro de 2014.
} 
no Brasil, de acordo com Santos (2009), uma das primeiras experiências colaborativas que utilizou o potencial interativo-criativo do texto eletrônico para criar junto aos leitores uma narrativa, foi a obra de Mário Prata intitulada "Anjos de Badaró", que durante seis meses foi escrita conforme as opiniões dos leitores sobre o destino tanto dos personagens, assim como do enredo, para posteriormente ser publicada em formato impresso.

Atualmente os leitores-autores utilizam plataformas de redes sociais como o Twitter e aplicativos como o Whatsapp para desenvolver histórias de modo colaborativo, tendo como exemplo disto a iniciativa do cineasta Tim Burton, que no ano de 2010, através de uma frase publicada no Twitter, criou uma história colaborativa junto à vários fãs sobre seu personagem Stainboy. Para dar segmento à narrativa era utilizada a hashtag \#BurtonStory e, a partir dos diferentes parágrafos que eram enviados diariamente, o autor retweetava os que haviam sido selecionados para a continuação em sua conta, criando um registro da história que foi finalizada em 6 de dezembro de 2010 (Figura 1).

Figura 1 - Continue a história usando \#BurtonStory

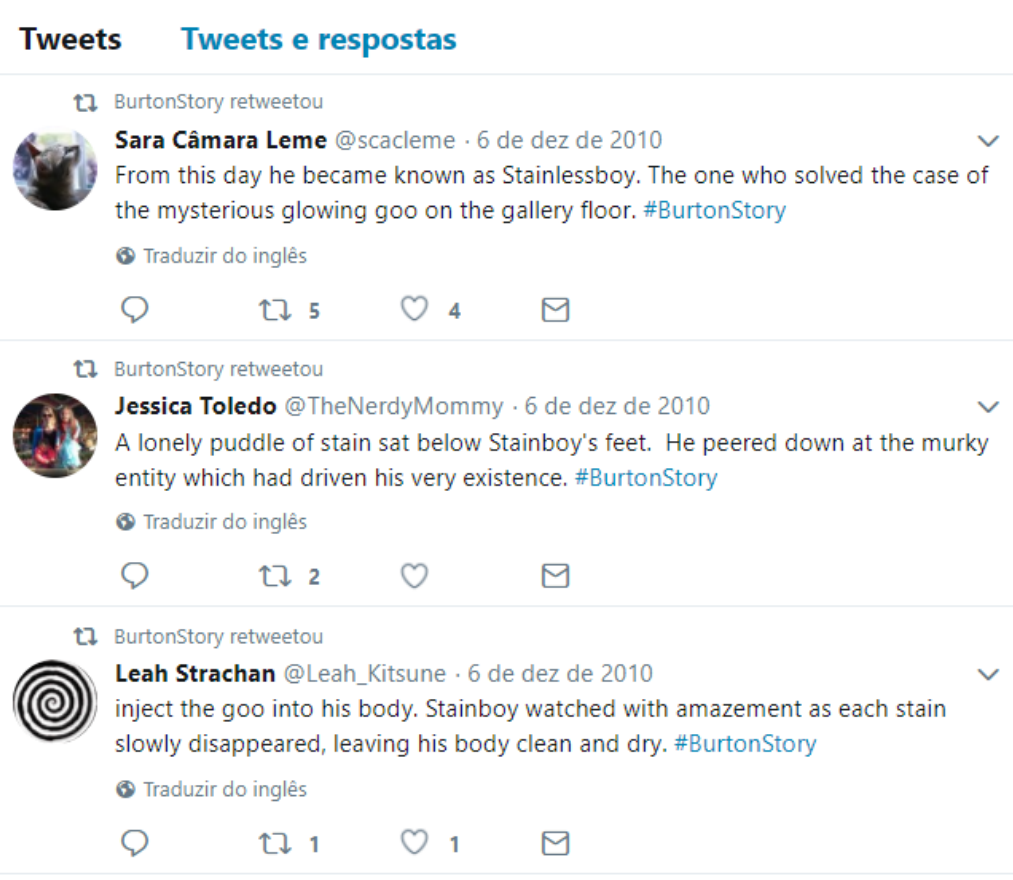

Fonte: <https://twitter.com/BurtonStory> Acesso em 20 dez. 2017

Apesar da existência de sites que possibilitam escrever histórias em co-autoria - Spirit Fanfiction ${ }^{5}$ é um exemplo disto (Figura 2) -, nota-se que são utilizadas diversas plataformas que não são específicas para construção e divulgação de narrativas colaborativas como, por exemplo, chats e redes sociais. Isso ocorre por motivos como a praticidade em unir diferentes usuários para a escrita, visto que, em sites como o Spirit Fanfiction, é necessário informar quem são os autores antes de enviar o primeiro capítulo da história, excluindo a possibilidade de entrada de novos escritores a qualquer momento do desenvolvimento da narrativa. Deste modo, a presente pesquisa encontra uma oportunidade de design e propõe a criação de um website que

\footnotetext{
${ }^{5}$ (https://www.spiritfanfiction.com/)
} 
proporcione aos usuários escritores de fanfictions um espaço para construir hiperficções colaborativas.

Figura 2 - Interface da página inicial, Spirit Fanfiction

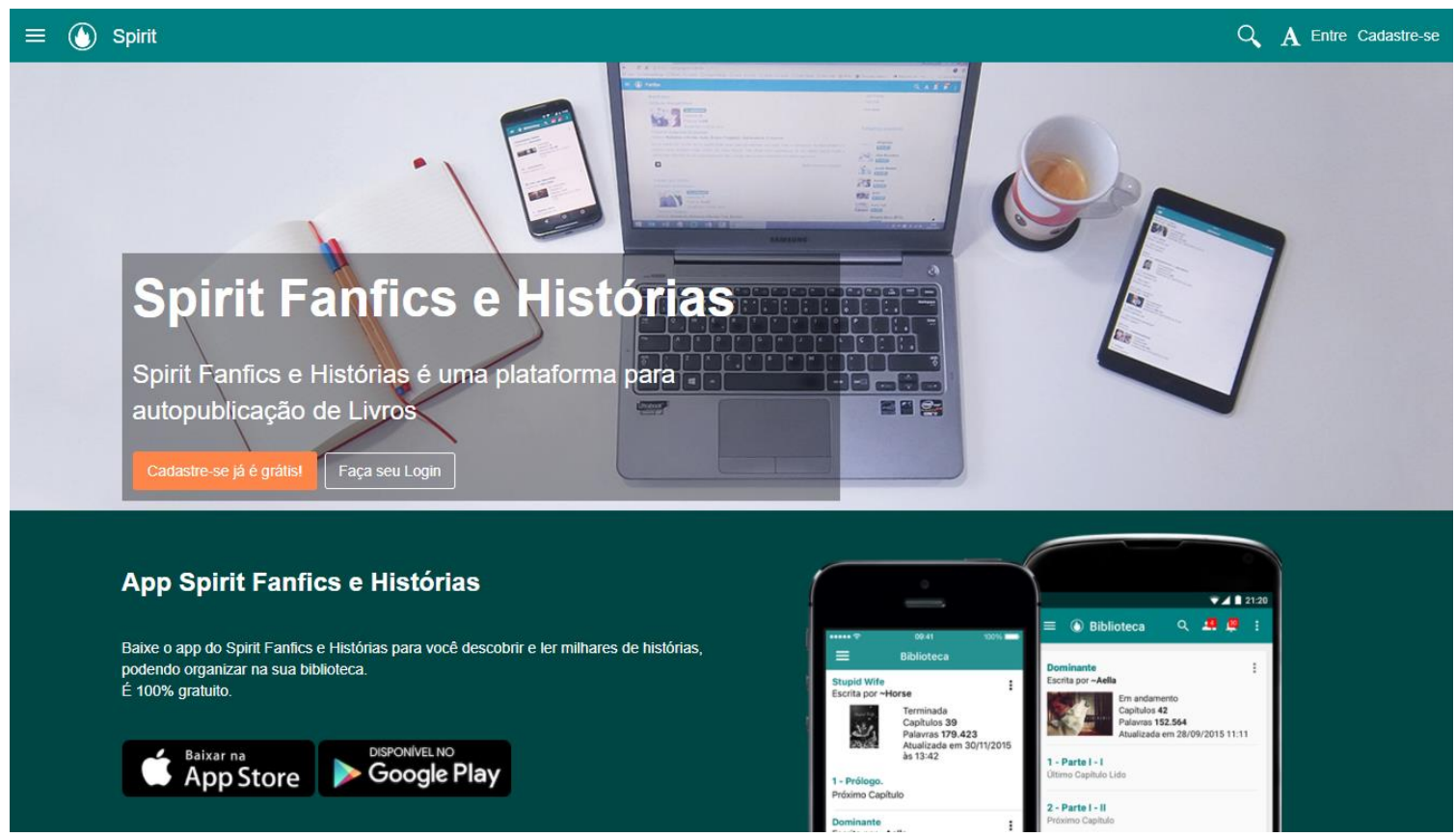

Fonte: < https://www.spiritfanfiction.com/ > Acesso em 29 mar. 2018

\subsection{Uma proposta para a construção colaborativa}

Ao pensar o processo criativo de escrita colaborativa como um projeto, se desenha fluxos de navegação possíveis para que os usuários participem ativamente em conjunto desse processo. Parte-se do princípio que os usuários já possuem a inspiração para a escrita, mas poucas são as plataformas pensadas exclusivamente para testar as potencialidades criativas e lançar desafios que fomentem a escrita colaborativa. Neste ponto, o design atua como um processo facilitador para a virtualização e organização do texto, pois é capaz de participar do desenvolvimento de plataformas específicas para a construção deste tipo de narrativa, intervindo com soluções centradas no usuário que otimizam a experiência de criação colaborativa.

Para isso, o website a ser criado projeta uma grande rede aleatória de colaboratividade a partir de uma temática lançada semanalmente, com breves descrições de problemática, personagens e universo. Cada usuário escreve um capítulo que corresponda aos desafios lançados. O próximo passo encontra-se na troca aleatória entre esses capítulos, em que os usuários deverão continuar desenvolvendo um segundo capítulo para a narrativa que foi escrita por outra pessoa e assim sucessivamente até que a história termine. Propõe-se assim, que a leitura e a escrita podem ser vistas como um exercício similar ao jogo cooperativo, com seus próprios players (os leitoresescritores), que precisam se unir e juntos cumprirem o objetivo (desenvolver e dar continuidade a narrativa).

O esquema a seguir (Figura 3), exemplifica como funcionaria esse processo de troca na escrita colaborativa. Cada cor representa as ramificações narrativas que surgiram a partir da 
temática lançada. Tendo quatro usuários são originadas quatro narrativas diferentes que estão representadas pela seguinte diferenciação de cores. As linhas contínuas representam a troca aleatória que foi feita entre os usuários e as linhas tracejadas identificam os capítulos que cada usuário escreveu.

Figura 3 - Esquema de fluxograma para escrita colaborativa

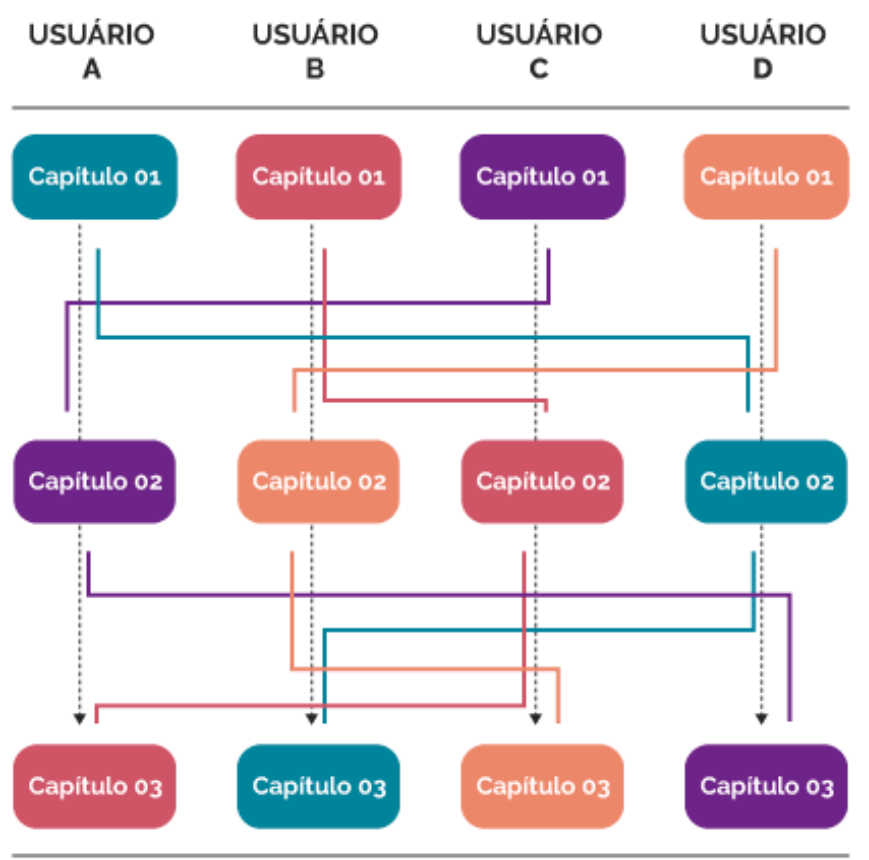

Fonte: as autoras

Observa-se que a narrativa simbolizada com a cor azul iniciou sendo escrita pelo usuário $A$, seu segundo capítulo foi desenvolvido pelo usuário $D$ e o terceiro pelo usuário $B$. É importante destacar que não existe um limite de usuários participando colaborativamente, podem ser quatro, dez ou trinta usuários diferentes. As trocas aleatórias de capítulos são geradas pelo sistema e, para que haja o controle da narrativa, o website lança junto com a temática as especificações quanto ao número de capítulos que devem ser escritos até o final das histórias.

Esse fluxo de escrita e leitura criado através de um projeto de design, resgata as características do gênero textual hiperficção, pois possibilita aos usuários o controle conjunto do texto, bem como a organização das informações. O potencial criativo e as perspectivas narrativas são conectadas diretamente a prática de escrita de fanfictions: os usuários são livres para desenvolver as linhas e ramificações narrativas como melhor desejarem, criando os personagens e os conflitos que acharem necessários e, baseando-se nisso, constrói-se a interatividade a partir da própria estrutura narrativa, assim como pontua Santos (2009).

\section{Conclusão}

Ao entender o processo de escrita de fanfictions, é reconhecida esta prática como um processo semelhante as narrativas hiperficcionais, pois ambos possuem um potencial criativo que pode utilizar a colaboratividade entre usuários para o desenvolvimento de histórias. Através do 
design promove-se uma ferramenta digital que oferece a possibilidade de construir hiperficções colaborativas virtualmente entre diversos usuários, utilizando fluxos aleatórios para tornar a criação de narrativas um método similar à cooperação em jogos e explorar as capacidades criativas dos usuários.

As inovações tecnológicas referentes à maleabilidade da narrativa são um meio de potencializar as possibilidades criativas, uma vez que é apresentada ao leitor a oportunidade de continuar a história. Trabalha-se diretamente com a capacidade de escolha e com a expectativa gerada a partir disto, fatores que influenciam diretamente em novas criações criativas.

Como estudos futuros relativos a esta pesquisa, propõe-se a aplicação do design na construção e prototipação desta ferramenta de escrita colaborativa. Busca-se validar, em conjunto com usuários, a eficiência do fluxo de leitura e escrita projetado.

\section{Referências}

BARBOSA, Pedro. (1998). A Renovação do Experimentalismo Literário na Literatura Gerada por Computador. In: Revista da UFP, n.ㅇ 2, p. 181-188, Porto - Portugal, 1998.

BLACK, Rebecca. Language, cultura and identity in online fanfiction. In: E- Learning, v. 3, n. 2, 2006.

CHARTIER, Roger. A aventura do livro: do leitor ao navegador. São Paulo: UNESP, 1998.

EISNER, Will. Narrativas Gráficas: princípios e práticas da lenda dos quadrinhos. 3.ed. São Paulo: Devir, 2013.

MURAKAMI, Raquel Yukie. O ficwriter e o campo da fanfiction: reflexão sobre uma forma de escrita contemporânea. 2016. Dissertação (Mestrado) -- Universidade de São Paulo, Faculdade de Filosofia, Letras e Ciências Humanas, Programa de Pós-Graduação em Teoria Literária e Literatura Comparada. Disponível em: <http://www.teses.usp.br/teses/disponiveis/8/8151/tde-10042017122630/pt-br.php> Acesso em: 27 out. 2017.

PAVÃO, Mauren Przybylski. Das materialidades da literatura: a reinvenção da vida e o acervo de narrativas orais urbano-digitais. 2014. Tese (Doutorado) -- Universidade Federal do Rio Grande do Sul, Instituto de Letras, Programa de Pós-Graduação em Letras, Porto Alegre, 2014. Disponível em: <http://www.lume.ufrgs.br/handle/10183/102227> Acesso em: 28 out. 2017.

SAMPAIO, Theane Neves. Universos Alternativos: Literatura e produção de sentido em sites de fanfictions. 2013. Dissertação (Mestrado) -- Pontifícia Universidade Católica do Rio de Janeiro, Departamento do Centro de Ciências Sociais, Programa de Pós-Graduação em Comunicação Social, Rio de Janeiro, 2013.

SANTOS, Marcelo da Silva Araújo. O processo de leitura hiperficcional: um estudo de caso com A dama de espadas. 2009. Dissertação (Mestrado) -- Universidade Estadual de Feira de Santana, Departamento de Letras e Artes, Programa de Pós-Graduação em Literatura e Diversidade Cultural, Feira de Santana, 2009. Disponível em:

<http://www.dominiopublico.gov.br/pesquisa/DetalheObraForm.do?select_action=\&co_obra=17 0377> Acesso em: $11 \mathrm{dez} .2017$.

SANTOS, Viviane da Silva. Gêneros textuais em ambiente digital e leitura: o caso da hiperficção 
exploratória. 2014. Dissertação (Mestrado) -- Universidade do Estado do Rio de Janeiro, Instituto de Letras, Rio de Janeiro, 2014. Disponível em:

<http://www.bdtd.uerj.br/tde_busca/arquivo.php?codArquivo=6983> Acesso em 11 dez. 2017.

SANTOS, Viviane da Silva; VERGANO-JUNGER, Cristina. Hiperficção e letramento na era digital. In: Revista Intercâmbio, v. XXX: 95-111, 2015. São Paulo: LAEL/PUCSP

VARGAS, Maria Lúcia Bandeira. O fenômeno fanfiction: novas leituras e escrituras no meio eletrônico. Passo Fundo: UPF Editora, 2015. 